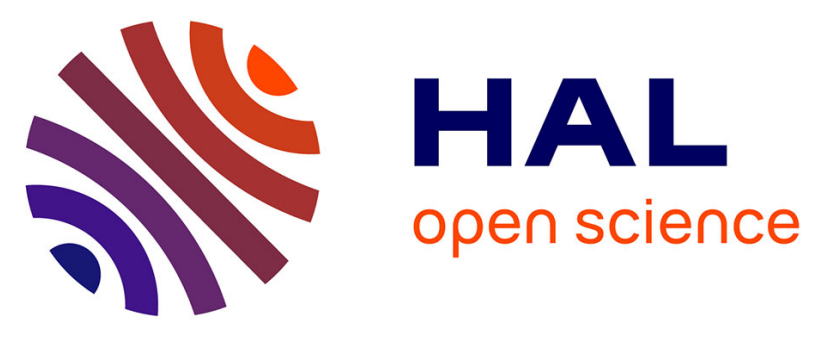

\title{
Speciation of Metals in Asphaltenes by High-Performance Thin-Layer Chromatography and Solid-Liquid Extraction Hyphenated with Elemental and Molecular Identification
}

Rémi Moulian, Martha Chacón-Patiño, Oscar Lacroix-Andrivet, Sandra Mounicou, Anna Luiza Mendes Siqueira, Carlos Afonso, Ryan Rodgers, Pierre Giust, Brice Bouyssière, Caroline Barrère-Mangote

\section{- To cite this version:}

Rémi Moulian, Martha Chacón-Patiño, Oscar Lacroix-Andrivet, Sandra Mounicou, Anna Luiza Mendes Siqueira, et al.. Speciation of Metals in Asphaltenes by High-Performance Thin-Layer Chromatography and Solid-Liquid Extraction Hyphenated with Elemental and Molecular Identification. Energy \& Fuels, 2020, 34 (10), pp.12449-12456. 10.1021/acs.energyfuels.0c02525 . hal-03043382

\section{HAL Id: hal-03043382}

https://hal-univ-pau.archives-ouvertes.fr/hal-03043382

Submitted on 25 Nov 2021

HAL is a multi-disciplinary open access archive for the deposit and dissemination of scientific research documents, whether they are published or not. The documents may come from teaching and research institutions in France or abroad, or from public or private research centers.
L'archive ouverte pluridisciplinaire $\mathbf{H A L}$, est destinée au dépôt et à la diffusion de documents scientifiques de niveau recherche, publiés ou non, émanant des établissements d'enseignement et de recherche français ou étrangers, des laboratoires publics ou privés. 


\section{Speciation of Metals in Asphaltenes by High-}

\section{Performance Thin-Layer Chromatography and Solid-}

\section{Liquid Extraction Hyphenated with Elemental and}

\section{Molecular Identification}

Rémi Moulian ${ }^{1,2,3}$, Martha Chacón-Patiño ${ }^{3,4}$, Oscar Lacroix-Andrivet ${ }^{3,5,6}$, Sandra Mounicou ${ }^{1,3}$, Anna Luiza Mendes Siqueira ${ }^{3,6}$, Carlos Afonso ${ }^{3,5}$, Ryan Rodgers ${ }^{1,3,4,7,}$, Pierre Giust ${ }^{2,3}$, Brice Bouyssiere $^{1,3}$, Caroline Barrère-Mangote ${ }^{2,3}$

${ }^{1}$ Universite de Pau et des Pays de l'Adour, E2S UPPA, CNRS, IPREM, Institut des Sciences Analytiques et de Physico-chimie pour l'Environnement et les Materiaux, UMR5254, Hélioparc, 64053 Pau, France,

${ }^{2}$ TOTAL Refining and Chemicals, Total Research and Technologies Gonfreville, BP 27, 76700, Harfleur, France

${ }^{3}$ International Joint Laboratory - iC2MC: Complex Matrices Molecular Characterization, TRTG, BP 27, 76700 Harfleur, France

${ }^{4}$ National High Magnetic Field Laboratory, Florida State University, 1800 East Paul Dirac Drive, Tallahassee, FL 32310 
${ }^{5}$ Normandie Université, COBRA, UMR 6014 et FR 3038, Université de Rouen, INSA de Rouen, CNRS, IRCOF, Mont Saint Aignan Cedex, France

${ }^{6}$ TOTAL Marketing Services, Research Center, 69360 Solaize, France

${ }^{7}$ Department of Chemistry and Biochemistry, 95 Chieftain Way, Florida State University, Tallahassee, FL 32306

${ }^{8}$ Future Fuels Institute, 1800 Paul Dirac Drive, Tallahassee, Florida 32310-4005, United States 


\section{ABSTRACT (267 words)}

Asphaltenes are among the most challenging components in petroleum processing because they contain high amounts of heteroatoms (i.e., $\mathrm{S}, \mathrm{N}, \mathrm{O}, \mathrm{V}$, and $\mathrm{Ni}$ ) thought to be responsible for strong aggregation tendencies, precipitation, and fouling problems. The role of vanadium and nickelcontaining petroleum compounds (i.e., "petroporphyrins") in aggregation and fouling is not completely understood because asphaltene composition and structure is still a subject of debate in the petroleum chemistry community. Characterization of asphaltenes, namely, molecular analysis that employs no chromatographic separation, often fails to reveal their comprehensive composition. The work herein presents asphaltene fractionation by 1) solid/liquid extraction, which allows for separation of single-core ("island") and multicore ("archipelago) structural motifs, and 2) high-performance thin layer chromatography (HPTLC) with cellulose as the stationary phase and $\mathrm{DCM} / \mathrm{MeOH}$ as the eluent, which facilitates access to petroporphyrins. Characterization is performed by laser ablation inductively coupled plasma mass spectrometry (LA-ICP-MS) and matrix-assisted laser desorption ionization Fourier transform ion cyclotron resonance mass spectrometry (MALDI FT-ICR MS). The results demonstrate that even with multiple separation steps, a large quantity of vanadyl porphyrins remains inaccessible for molecular analysis by MALDI FT-ICR MS, which raises the question of what portion of a complex sample of asphaltene can be revealed by ultrahigh resolution mass spectrometry. Furthermore, the results show that easily accessible porphyrins migrate with the solvent front in HPTLC. Thus, HPTLC can be used to isolate and identify "free" porphyrins, not locked into asphaltene aggregates; however, further development of separation methods is required to access the most difficult and problematic asphaltene fractions, which do not migrate and impose analytical challenges due to their stronger aggregation tendency. 
Keywords: MALDI, Porphyrins, Asphaltenes, HPTLC, Vanadium, FT-ICR MS, LA-ICP-MS 


\section{INTRODUCTION (772 words)}

Asphaltenes are well known for their negative impact on petroleum production, transportation, storage, and refining. Asphaltenes contain a wide diversity of molecules with different degrees of aromaticity, heteroatom contents, and molecular structure. For instance, Fourier transform ion cyclotron resonance mass spectrometry (FT-ICR MS) has revealed asphaltene molecules with either single-core or multicore structures that contain only hydrogen and carbon (hydrocarbons or the $\mathrm{HC}$ class) as well as species with up to three or more heteroatoms (e.g., vanadyl porphyrins or the $\mathrm{N}_{4} \mathrm{O}_{1} \mathrm{~V}_{1}$ class, sulfur-containing molecules or the $\mathrm{S}_{3}$ class, and oxygen-rich compounds or the $\mathrm{O}_{4}$ class) [1]-[6]. Thus, the combined effects of aromaticity, heteroatom content, and molecular structure trigger multiple intermolecular interactions, such as pi-stacking, hydrogen bonding, acidbase conjugations, and London dispersion forces between asphaltenes. The synergy between multiple intermolecular interactions results in strong aggregation and ultimate precipitation of a wide compositional range of species, from those with no heteroatoms (HC class) to high heteroatom-containing species [7], [8], [9]. It is believed that metals present in asphaltenes are mainly present in porphyrinic complexes [10]-[12], i.e., nickel and vanadyl porphyrins are tetrapyrrole-based metal complexes. The actual structures of nickel and vanadyl porphyrins are the result of geochemical modifications of the chlorophyll molecule. The chlorophyll structure changed over geological time during fossil crude oil formation via demetallation, aromatization, and peripheral addition of sulfur or oxygen [13], [14]. These transformations yielded several

structurally different porphyrin families of the types $\mathrm{N}_{4} \mathrm{O}_{1} \mathrm{~V}_{1}, \mathrm{~N}_{4} \mathrm{O}_{2} \mathrm{~V}_{1}, \mathrm{~N}_{4} \mathrm{O}_{3} \mathrm{~V}_{1}, \mathrm{~N}_{4} \mathrm{O}_{1} \mathrm{~V}_{1} \mathrm{~S}_{1}$ and $\mathrm{N}_{4} \mathrm{Ni}$, as shown in Figure 1.

Understanding the molecular composition of porphyrins and other metal complexes that trigger issues in refinery processes is critical to the petroleum industry. For this purpose, it is essential to 
fractionate asphaltenes before molecular-level analysis because direct "dilute-and-shoot" studies of such a complex matrix usually do not reveal a great part of the information. As shown by Evdokimov et al [15], [16], even with the abundant presence of petroporphyrins, the Soret band, characteristic of porphyrinic complexes in ultraviolet absorption spectra, is not always detected in the sample spectrum, the detection of which depends on the dilution factor. Furthermore, with MS techniques such as matrix-assisted laser desorption ionization (MALDI) FT-ICR MS, the matrix, ionization efficiency, and ion suppression effects usually conceal the molecular level of difficultto-ionize compounds. Recently, Chacón-Patiño et al [17] and Giraldo-Davila et al [18] used silica gel thin-layer chromatography plates to separate asphaltene samples and achieve a more complete molecular characterization. The authors used a mixture of $\mathrm{DCM} / \mathrm{MeOH}$, followed by toluene, to separate asphaltenes into three fractions enriched in alkyl-aromatic compounds, polar species, and noneluted asphaltenes. This technique can also be used on the preparative scale to separate fractions that can then be extracted with solvents and further analyzed by other techniques ( $\mathrm{Li}$ et al [19]). Furthermore, asphaltene samples can also be separated prior to high-performance thin layer chromatography (HPTLC) analysis. For example, Chacón-Patiño et al [5], [20], [21] reported asphaltene fractionation by a solid-liquid extraction strategy using silica gel as an adsorbent and subsequent Soxhlet extraction; this method is known as extrography. The authors demonstrated that extrography allows for the separation of asphaltenes according to their structural motif, multicore or archipelago (composed of several aromatic cores linked by covalent bonds) and single-core or island (composed of one aromatic core with alkyl side chains). According to these results, island compounds are easily accessed by atmospheric pressure photoionization FT-ICR MS; conversely, archipelago molecules are more difficult to ionize, due in part to their relatively stronger aggregation trends[22]. 
The use of TLC or HPLTC allows for more comprehensive elemental information for petroleum fractions [23], [24]. For instance, Chirinos et al [25] used laser ablation ICP-MS to achieve rapid determination of the ratio between nickel and vanadium in asphaltene samples after a separation step with HPTLC. Moreover, the use of HPTLC plates also allows for molecular analysis by LDI/MALDI FT-ICR MS; for example, Cho et al [26] demonstrated that LDI FT-ICR MS can be used to quantify porphyrins in petroleum samples. Additionally, Pradilla et al[27] developed a MALDI matrix to promote selective ionization or petroporphyrins via electron transfer reactions. The authors used a novel matrix to analyze asphaltenes after an HPTLC separation step. The results revealed the selective ionization of petroporphyrins and an increased number of molecular formulas compared to those identified in previous studies [4].

In this work, two successive separation steps, extrography and HPTLC, were coupled with elemental laser ablation inductively coupled plasma mass spectrometry (LA-ICP-MS) and molecular detection (MALDI FT-ICR MS) to characterize metals contained in one asphaltene reference sample, referred to as Asphaltene 2017. The purpose was to determine which fractions contained vanadium and the kinds of porphyrins present in these fractions.

\section{EXPERIMENTAL SECTION (818 WORDS)}

Samples and Reagents. Samples. Asphaltene 2017 (from a Middle Eastern crude oil, Vanadium content: $640 \mathrm{ppm}$ ) from the interlaboratory study of the Petrophase 2017 Conference [28] and its extrography fractions, prepared as reported by Chacon-Patiño[5], [20], were studied. Asphaltene 2017 was obtained by a slightly modified version of the ASTM D6560-12 method. A cleaning step, via four cycles of maceration and Soxhlet extraction with heptane, was employed to decrease the amount of occluded/coprecipitated maltenes. 
Solvents. Tetrahydrofuran (THF, HPLC grade, without stabilizer, Lichrosolv, Merck, Frankfurter Strasse 250 Darmstadt, 64293, Germany) was used as the solvent for sample preparation and for MALDI analyses. Dichloromethane (DCM) and methanol (MeOH) (HPLC grade, Lichrosolv, Merck, Frankfurter Strasse 250 Darmstadt, 64293, Germany) were used to develop the HPTLC plates. Toluene, heptane, and pentane were used to prepare Petrophase 2017 asphaltenes. Acetone, toluene, heptane, THF and methanol of HPLC grade were used to prepare extrography fractions from Asphaltene 2017.

\section{Solid/liquid extraction samples}

Extrography fractionation was carried out following a method reported elsewhere [20]. Briefly, a Soxhlet apparatus was used to perform three successive extractions. Approximately $150 \mathrm{mg}$ of asphaltenes was dissolved in dichloromethane, and $15 \mathrm{~g}$ of silica was then added to the solution. Subsequently, the mixture was completely dried under nitrogen, and the dried mixture was Soxhlet extracted with acetone, toluene/heptane (50/50 Hep/Tol, v/v), and toluene/tetrahydrofuran/methanol (47.5/47.5/5 Tol/THF/MeOH, v/v/v).

\section{Instrumentation.}

\section{HPTLC Plates.}

Cellulose HPTLC glass plates (Merck, thickness 0.15-0.2 mm, Frankfurter Strasse 250 Darmstadt, 64293, Germany) that were $20 \mathrm{~cm} \times 10 \mathrm{~cm}$ in size and did not contain fluorescent indicators were used. The HPTLC procedure was carried out with the following instrumentation protocol from CAMAG. Sample application and sample development were performed using automatic TLC Sampler 4 (ATS4) and automated multiple development 2 (AMD2) equipment. UV absorbance chromatograms were acquired at a wavelength of $280 \mathrm{~nm}$ with a D2 \& W lamp TLC scanner. UV spectra from $190 \mathrm{~nm}$ to $900 \mathrm{~nm}$ were obtained using the same device. Finally, a 
TLC visualizer was used to obtain images of the cellulose plate under $366 \mathrm{~nm}$ UV light after development. Peak area data were determined using WinCATS software.

HPTLC plates were cleaned with DCM and THF and dried at $110^{\circ} \mathrm{C}$ for 10 min prior to sample deposition. All the samples were deposited $10 \mathrm{~mm}$ from the bottom of the plate. A high eluentstrength mobile phase (DCM:MeOH, 99.5:0.5) was used. The plate was developed in a single step until the solvent front reached $50 \mathrm{~mm}$. Whole Petrophase 2017 and its extrography fractions were deposited two times per HPTLC plate on three different plates that were developed as described above for subsequent analysis by LA-ICP-MS.

Developed HPTLC separations for whole Petrophase 2017 and its three extrography fractions were also subjected to MALDI FT-ICR MS analysis. After separation, the different samples were scratched from the plates, and extraction using THF was performed and mixed with a custom synthetized MALDI matrix (matrix:sample ratio of 1) developed by the Combariza Research Group [4], [27], [29]. The MALDI matrix, facilitated porphyrin ionization by electron transfer reactions and is known as $\alpha$-cyanophenylenevinylene ( $\alpha$-CNPV-CH3).

\section{LA-ICP-MS}

Element-specific analyses of the developed HPTLC plates were carried out by LA-ICP-MS using a New Wave Research UP-213 Nd:YAG laser (ESI, Fremont, CA) coupled with ICP-MS (7700 series, Agilent, Santa Clara, CA) [24] under the operating conditions given in Table 1. The instrument was equipped with a Fassel-type quartz torch shielded with a grounded Pt electrode and a quartz bonnet; a standard quartz injector ( $1.75 \mathrm{~mm}$ i.d.) was used. An ablation chamber was installed on a three-axis translation stage and coupled to the ICP torch using a $60 \mathrm{~cm}$ Tygon tube 
(5.0 $\mathrm{mm}$ i.d.). The ablated material was swept by the carrier gas (helium) and mixed with the spectrometer makeup gas (argon) prior to introduction into the plasma. Ni sampler (orifice diameter: $1.1 \mathrm{~mm}$ ) and skimmer (orifice diameter: $0.8 \mathrm{~mm}$ ) cones were optimized for the analyses [24]. The laser beam followed a linear trajectory throughout the migration. To fit within the ablation cell, plates were cut to dimensions of $9 \times 10 \mathrm{~cm}^{2}$. Each sample on the three different plates was analyzed in triplicate.

\section{MALDI FT-ICR MS}

A hybrid quadrupole FT-ICR instrument (SolariXR, Bruker Daltonics, Bremen, Germany) equipped with a $12 \mathrm{~T}$ superconducting magnet was equipped with an LDI/MALDI source with an $\mathrm{Nd}: Y A G \times 3$ solid-state laser $(355 \mathrm{~nm})$ [30]. Broadband mass spectra were acquired over a mass range of $m / z 147-1,000$ with an accumulation of 200 scans. The signal was digitalized with $8 \mathrm{M}$ points, resulting in a transient length of $3.4 \mathrm{~s}$, giving a resolving power number of $0.910^{6}$ at $\mathrm{m} / \mathrm{z}$ 400. Instrument control and data acquisition were facilitated by DataAnalysis (version 4.4); OriginPro (version 2016) was used to process and visualize the data. From the molecular formulas determined from the accurate mass measurements (typically $<0.2 \mathrm{ppm}$ ), double bond equivalent (DBE) values were calculated as shown in equation 1 (c: carbon number; h: hydrogen number; $\mathrm{n}$ : nitrogen number)[31].

$$
D B E=c-\frac{h}{2}+\frac{n}{2}+1
$$

\section{Equation 1. DBE}

\section{RESULTS (829 words)}




\section{HPTLC results}

Four asphaltene samples, the whole Petrophase 2017 asphaltene sample (A2017) and its three extrography fractions (acetone, Hep/Tol, and Tol/THF/MeOH), were separated via HPTLC and analyzed with a UV densitometer. UV analysis at $280 \mathrm{~nm}$ of the developed HPTLC plates (Figure 2 A) demonstrates that the samples were separated into two major fractions, eluted and noneluted.

Figure 2 B features the complete UV spectra for the eluted and noneluted fractions. The results demonstrate that all noneluted fractions have a similar spectrum, in which the absorbance reaches a maximum at $\sim 240 \mathrm{~nm}$ and then decreases continuously until $\sim 800 \mathrm{~nm}$. However, the eluted HPTLC fractions present different trends. For instance, the Tol/THF/MeOH extrography fraction features an absorption spectrum with a weaker signal between 400 and $600 \mathrm{~nm}$ than those of the other fractions. Eluted species from whole PetroPhase 2017 and its Hep/Tol extrography fraction present similar absorption spectra. Finally, the acetone extrography fraction shows the Soret band ( $\sim 20 \mathrm{~nm}$, indicated with a star), which is characteristic of porphyrins.

Table 2 shows the results for average quantification for the three developed HPTLC plates. Combined with the data shown in Figure 2, the results indicate that only $\sim 9 \%$ of the Tol/THF/MeOH extrography fraction migrates up to the solvent front. For the acetone fraction, there is 53\% migration. Whole asphaltenes and their Hep/Tol fraction present a similar migration of 28 and $23 \%$, respectively. The results suggest that species in the acetone fraction are less prone to strong adsorption issues on polar surfaces such as cellulose. 
Trends of Elemental Composition as a Function of Migration. HPTLC plates were analyzed by LA-ICP-MS to quantify vanadium in the eluted/noneluted fractions. The results are presented in Figure 3, Figure S1 and summarized in Table 3, and corroborate compositional similarities between whole PetroPhase 2017 asphaltenes and its Hep/Tol extrography fraction (panels A and C): for both samples, ${ }^{51} \mathrm{~V}$ is present at the deposition point (noneluted fraction) and the solvent front (eluted species). Regarding the acetone fraction, Figure 3 B demonstrates that all vanadiumcontaining compounds migrated with the solvent front. Conversely, the Tol/THF/MeOH fraction revealed vanadium compounds that remained in the noneluted HPTLC fraction. The quantitative results shown in Table 3 demonstrate that $\sim 100 \%$ of ${ }^{51} \mathrm{~V}$-containing compounds $(\sim 20,000 \mathrm{cps})$ in the acetone fraction migrated to the solvent front, whereas $100 \%$ of vanadium species in the Tol/THF/MeOH ( 30,000 cps) fraction remained noneluted.

\section{Molecular-Level Characterization by FT-ICR MS}

MALDI FT-ICR MS characterization was facilitated by the use of a novel matrix designed to favor electron transfer reactions for the efficient ionization of metal complexes, such as vanadyl porphyrins [4], [27]. This MALDI matrix is a phenylenevinylene derivative that allows for greater ion abundances of porphyrin-like molecules and limits the ionization of other compounds, such as alkyl-substituted PAHs, which are also present in asphaltenes. MALDI FT-ICR spectra were collected for all samples at the deposition point (noneluted fraction) and the solvent front (eluted fraction). Molecular formulas were assigned to the mass spectral peaks and sorted by heteroatom class (e.g., $\mathrm{N}_{4} \mathrm{O}_{1} \mathrm{~V}_{1}$ or vanadyl porphyrins), carbon number, and double bond equivalents $(\mathrm{DBE}=$ number of rings plus double bonds). At the sample deposition point (noneluted fraction), porphyrins were not detected in the whole asphaltene sample or in all extrography fractions. Thus, 
at the deposition point, vanadium-containing compounds detected by LA-ICP-MS were not ionized (as monomers) by MALDI, even when utilizing a specific matrix designed to enhance the ionization of vanadyl porphyrins. The results highlight the limitations of mass spectrometry to access the complete molecular composition of one of the most complex/challenging samples, the asphaltenes.

Figure 4 presents isoabundance color-contoured plots of DBE versus carbon number for vanadyl porphyrins $\left(\mathrm{N}_{4} \mathrm{O}_{1} \mathrm{~V}_{1}\right.$ class $)$ and heteroatom-substituted counterparts $\left(\mathrm{N}_{4} \mathrm{O}_{2} \mathrm{~V}_{1}\right.$ and $\mathrm{N}_{4} \mathrm{O}_{1} \mathrm{~S}_{1} \mathrm{~V}_{1}$ classes) for all eluted HPTLC fractions. In these plots, the color scale represents the relative abundance. For the $\mathrm{N}_{4} \mathrm{O}_{1} \mathrm{~V}_{1}$ class (Figure 4 A), the most abundant components (red data points) for all samples present the same carbon number (29/30) and DBE values (18). Molecular formula for DBE for all the samples are presented in Table S1. Thus, the results suggest that the PetroPhase 2017 asphaltene sample contains abundant DPEP-type porphyrins.

For the whole PetroPhase 2017 asphaltene sample, 146 molecular formulas were found; the most abundant compounds feature DBE values of 17 and 18, which indicates the dominance of Etio and DPEP porphyrins. The Hep/Tol and Tol/THF/MeOH extrography fractions only revealed 44 and 7 porphyrins species. Conversely, the acetone fraction featured the highest content of vanadyl porphyrins, as revealed by 254 molecular formulas obtained via mass spectrometry. In Figure 4 B, porphyrins with one additional oxygen atom were only found in whole asphaltenes and the acetone fraction with a 3.3 and 2.2-fold lower relative abundance than the $\mathrm{N}_{4} \mathrm{O}_{1} \mathrm{~V}_{1}$ class. Figure 4 $\mathbf{C}$ indicates that porphyrins with one sulfur atom, only detected in the acetone fraction, have abundant homologous series with DBE values from 22 to 30 and carbon numbers between 25 and 50. The higher DBE values are consistent with $\mathrm{S}$ incorporated as e.g., thiophene and benzothiophene peripheral groups. 


\section{DISCUSSION (829 words)}

In Figure 2 B, the spectra obtained for the noneluted fractions for all samples are remarkably similar and are characteristic of a complex mixture of polyaromatic compounds. For the eluted HPTLC fractions, the Soret band at $420 \mathrm{~nm}$ was only evident in the acetone extrography fraction. As shown by Evdokimov et al [15], porphyrins can be "invisible" in UV-Vis spectroscopy due to aggregation. Thus, our results suggest that separation by HPTLC allows for the isolation of porphyrins that are not bound in asphaltene aggregates, as already proposed in our previous paper [32].

For the whole PetroPhase 2017 sample, the results obtained by UV (Figure 2) and laser ablation (Figure 3) are quite similar to our previous results [32]. Indeed, nearly $80 \%$ of the vanadium remained at the deposition point (Table 3, LA-ICP-MS analysis). In that work, the Asphaltene 2017 sample was also analyzed by MALDI FT-ICR MS, but no porphyrins were detected at the deposition point. The results suggest that vanadium-containing molecules, such as porphyrins (whole asphaltenes/deposition point), are present but are not easily accessible, likely because of aggregation. These results are consistent with the UV spectroscopy behavior. Putman et al[33] has reported limitations in MS characterization of asphaltenes due to low ionization efficiency of specific chromatography fractions. In this work, according to Table $\mathbf{3}$ and Figure $4 \mathbf{A}$, approximately $80 \%$ of molecules containing vanadium could not be identified via ultrahighresolution mass spectrometry. This raises questions about what portion can be analyzed with such techniques even with previous separation steps. Furthermore, in Figure 4 B, porphyrins with one additional oxygen atom were only found in PetroPhase 2017 sample and the acetone fraction in both case at the eluted point with a lower relative abundance (3.34 and 2.25 times less). The UV 
results for the Hep/Tol fraction were quite similar (Figure 2) to those of the whole PetroPhase 2017 sample. However, according to elemental analysis, vanadium was present at a lower concentration at the eluted point (5\%) for the Hep/Tol fraction than for the whole PetroPhase 2017 sample (20\%). In MALDI-FT-ICR MS, the abundance of porphyrins at the eluted point was lower in the Hep/Tol fraction than in the whole sample. Collectively, the results suggest that the whole PetroPhase 2017 asphaltene sample and the Hep/Tol extrography fraction contained free and aggregate-bound porphyrins.

HPTLC-LA-ICP-MS analysis (Figure 3 D) of the Tol/THF/MeOH extrography fraction indicates that ${ }^{51} \mathrm{~V}$ is only present at the deposition point; however, no Soret band was detected by UV-Vis spectroscopy (Figure 2 B). For MALDI FT-ICR MS experiments, despite the use of the custom MALDI matrix for selective ionization of metal complexes, no porphyrins were detected at the deposition point. Thus, noneluted vanadium-containing compounds are not easily accessible and could be trapped into asphaltene aggregates that prevent their detection by UV-Vis spectroscopy and as monomers in FT-ICR MS. The eluted fraction ( $8.8 \%$ in UV) from Tol/THF/MeOH presents a vanadium content below the LA-ICP-MS detection limit. However, it reveals $7 \mathrm{~N}_{4} \mathrm{O}_{1} \mathrm{~V}_{1}$ molecular formulas; such compounds could be completely "free" or present on the aggregate surface and therefore available for MS analyses. As reported by Chacon-Patiño [20], the Tol/THF/MeOH extrography fraction contains abundant multicore motifs ("archipelago") and heteroatom-rich compounds. This fraction exhibits stronger aggregation trends and may comprise the most problematic asphaltene species that are likely responsible for demetallation problems in refineries. 
Conversely, the acetone fraction presents the highest intensities for the three different types of porphyrins (Figure 4), and the Soret band present in the UV-Vis spectrum (Figure 2) at the eluted point suggests a high amount of easily accessible porphyrins. The most abundant molecular formulas have the same carbon number and DBE values as those found for other samples (whole asphaltenes, Hep/Tol, and Tol/THF/MeOH). These results suggest that the easily accessible porphyrins are likely the same compounds in all four samples and were concentrated in the acetone fraction, which exhibits weaker adsorption on polar surfaces (i.e., cellulose) and weaker aggregation tendencies than for the other solvents; therefore, it is likely that porphyrins were not locked into aggregates in this fraction. Furthermore, the UV results in Figure 2 A suggest that a portion of the sample (47\%) remained at the deposition point, but no vanadium was found by the elemental LA-ICP-MS and molecular-level FT-ICR-MS analyses. These results suggest that Soxhlet extraction, coupled with HPTLC, allows for the separation of free porphyrins from those that are locked into asphaltene aggregates. The results indicate that the vanadium present in the acetone extrography fraction is easily accessible and constitutes "free" porphyrins. Chacon-Patiño et al [5] demonstrated that acetone fractions from geologically diverse asphaltene samples are enriched in single-core or "island" type asphaltenes [20]. Therefore, the results indicate that vanadyl porphyrins in the acetone fraction exhibit weak intermolecular interactions with asphaltene aggregates mostly comprised of single-core motifs; HPTLC separation by cellulose plates and DCM solvent can disrupt those interactions. Conversely, vanadyl porphyrins linked to multicore-type asphaltenes in the Tol/THF/MeOH extrography fraction are strongly linked to the nanoaggregates, which precludes their elution during HPTLC separation.

\section{CONCLUSIONS (271 words)}


Our previous works [32] using GPC-HPTLC with LA-ICP-MS suggest that porphyrins that migrate until the solvent front using $\mathrm{DCM} / \mathrm{MeOH}$ were more accessible as free porphyrins than those that remained at the deposition point. Here, extrography followed by HPTLC separation was used on asphaltene samples. Then, molecular and elemental detection to analyze vanadium and vanadyl porphyrins was successfully used. The combination of molecular and elemental analyses proved that a large quantity of porphyrins remained inaccessible to molecular analyses because of matrix effects and ionization preferences and that these porphyrins are linked to "archipelago" asphaltenes. The MALDI FT-ICR MS analyses showed that in all the samples, porphyrins that migrate until the solvent front are easier to analyze than those that remain at the deposition point. The acetone fraction showed a great quantity of easily ionizable porphyrins that migrated entirely until the solvent front. These results suggest that there was a high quantity of "free" porphyrins or porphyrins with weak interactions with the "island" nanoaggregates in the acetone fraction. In contrast, the Tol/THF/MeOH fraction, which contains a great quantity of vanadium, remains at the deposition point and gives almost no signal by MALDI-FT-ICR MS, which proves the strong interaction between porphyrins and "archipelago" type nanoaggregates or an effective occlusion of the porphyrins into the nanoaggregates. These results suggest that when ultrahigh-resolution mass spectrometry is used on asphaltene samples, even after previously using a separation step, only a part of the molecular complex structure can be revealed. Further works should concentrate on the noneluted part of the Hep/Tol and Tol/THF/MeOH fractions to determine the kinds of porphyrins present and their links with the asphaltene matrices.

\section{Supporting Information}

Figure S1. Six points calibration with vanadyl porphyrins after HPTLC separation and concentration obtained for the four samples by HPTLC-LA-ICP-MS. 
Table S1. Molecular formula, mass error and signal to noise ratio for all the vanadyl porphyrins signal at DBE 18 for all the four samples.

\section{AUTHOR INFORMATION}

\section{Corresponding Author}

Tel: +33 (0) 235551102

Email: caroline.mangote@total.com

Tel: +33 (0) 559407752

Email: brice.bouyssiere@univ-pau.fr

\section{Notes}

The authors declare no competing financial interests

\section{ACKNOWLEDGMENTS}

The authors would like to thank TOTAL for supplying the oil samples. Work performed at the National High Magnetic Field Laboratory ICR User Facility was supported by the National Science Foundation Division of Chemistry through Cooperative Agreements DMR-1157490 and DMR-1644779 and the state of Florida. This work was also supported by Conseil Régional d'Aquitaine (20071303002PFM) and FEDER (31486/08011464). The authors would like to thank the EU for funding via the ERC PRIMCHEMproject (No. 636829). This work was supported at Chimie Organique Bioorganique Réactivité Analyse (COBRA) laboratory by the European Regional Development Fund (ERDF)N³1708, the Région Normandie, and the Laboratoire LabEx 
SynOrg (ANR-11-LABX-0029). The authors would also like to thank Professor Marianny Y. Combariza, University of Santander-Colombia, for providing the matrix used for MALDI analysis during this work. 


\section{REFERENCES}

[1] O. P. Strausz, P. Peng, et J. Murgich, « About the Colloidal Nature of Asphaltenes and the MW of Covalent Monomeric Units », Energy \& Fuels, vol. 16, nº 4, p. 809-822, july 2002, doi: 10.1021/ef0002795.

[2] C. Leyva, J. Ancheyta, C. Berrueco, et M. Millán, « Chemical characterization of asphaltenes from various crude oils », Fuel Processing Technology, vol. 106, p. 734-738, feb. 2013, doi: 10.1016/j.fuproc.2012.10.009.

[3] T. M. C. Pereira et al., «An evaluation of the aromaticity of asphaltenes using atmospheric pressure photoionization Fourier transform ion cyclotron resonance mass spectrometry APPI( \pm )FT-ICR MS », Fuel, vol. 118, p. 348-357, feb. 2014, doi: 10.1016/j.fuel.2013.10.062.

[4] J. S. Ramírez-Pradilla, C. Blanco-Tirado, M. Hubert-Roux, P. Giusti, C. Afonso, et M. Y. Combariza, "Comprehensive Petroporphyrin Identification in Crude Oils Using Highly Selective Electron Transfer Reactions in MALDI-FTICR-MS », Energy \& Fuels, april 2019, doi: 10.1021/acs.energyfuels.8b04325.

[5] M. L. Chacón-Patiño, S. M. Rowland, et R. P. Rodgers, "Advances in Asphaltene Petroleomics. Part 3. Dominance of Island or Archipelago Structural Motif Is Sample Dependent», Energy \& Fuels, vol. 32, n ${ }^{\circ}$ 9, p. 9106-9120, sept. 2018, doi: 10.1021/acs.energyfuels.8b01765.

[6] T. Ghislain, L. Molnárné Guricza, et W. Schrader, « Characterization of crude oil asphaltenes by coupling size-exclusion chromatography directly to an ultrahigh-resolution mass spectrometer: Characterization of crude oil asphaltenes ", Rapid Communications in Mass Spectrometry, vol. 31, no 6, p. 495-502, march 2017, doi: 10.1002/rcm.7814.

[7] A. M. McKenna, A. G. Marshall, et R. P. Rodgers, «Heavy Petroleum Composition. 4. Asphaltene Compositional Space », Energy \& Fuels, vol. 27, nº 3, p. 1257-1267, march 2013, doi: 10.1021/ef301747d.

[8] H. W. Yarranton et al., " On the Size Distribution of Self-Associated Asphaltenes », Energy \& Fuels, vol. 27, no 9, p. 5083-5106, sept. 2013, doi: 10.1021/ef400729w.

[9] M. R. Gray, R. R. Tykwinski, J. M. Stryker, et X. Tan, « Supramolecular Assembly Model for Aggregation of Petroleum Asphaltenes », Energy \& Fuels, vol. 25, nº 7, p. 3125-3134, july 2011, doi: 10.1021/ef200654p.

[10] Y. Y. Borisova et al., « Role of Vanadylporphyrins in the Flocculation and Sedimentation of Asphaltenes of Heavy Oils with High Vanadium Content », Energy \& Fuels, vol. 31, no 12, p. 13382-13391, dec. 2017, doi: 10.1021/acs.energyfuels.7b02544.

[11] H. Santos Silva et al., " The role of metalloporphyrins on the physical-chemical properties of petroleum fluids », Fuel, vol. 188, p. 374-381, jan. 2017, doi: 10.1016/j.fuel.2016.10.065.

[12] D. H. Freeman, D. C. Saint Martin, et C. J. Boreham, « Identification of metalloporphyrins by third-derivative UV/VIS diode array spectroscopy », Energy \& Fuels, vol. 7, no 2, p. 194-199, march 1993, doi: 10.1021/ef00038a006.

[13] R. H. Filby et G. J. Van Berkel, « Geochemistry of Metal Complexes in Petroleum, Source Rocks, and Coals: An Overview », in Metal Complexes in Fossil Fuels, vol. 344, R. H. Filby et J. F. Branthaver, Éd. Washington, DC: American Chemical Society, 1987, p. 2-39.

[14] T. D. Lash, "Geochemical origins of sedimentary benzoporphyrins and tetrahydrobenzoporphyrins », Energy \& Fuels, vol. 7, no 2, p. 166-171, march 1993, doi: 10.1021/ef00038a001. 
[15] I. N. Evdokimov, N. Yu. Eliseev, et B. R. Akhmetov, « Assembly of asphaltene molecular aggregates as studied by near-UV/visible spectroscopy », Journal of Petroleum Science and Engineering, vol. 37, no 3-4, p. 135-143, march 2003, doi: 10.1016/S0920-4105(02)00350-9.

[16] I. N. Evdokimov, A. A. Fesan, et A. P. Losev, « Occlusion of Foreign Molecules in Primary Asphaltene Aggregates from Near-UV-Visible Absorption Studies », Energy \& Fuels, vol. 31, no 2, p. 1370-1375, feb. 2017, doi: 10.1021/acs.energyfuels.6b02826.

[17] M. L. Chacón-Patiño, C. Blanco-Tirado, J. A. Orrego-Ruiz, A. Gómez-Escudero, et M. Y. Combariza, «High Resolution Mass Spectrometric View of Asphaltene-SiO 2 Interactions », Energy \& Fuels, vol. 29, n 3, p. 1323-1331, march 2015, doi: 10.1021/ef502335b.

[18] D. Giraldo-Dávila, M. L. Chacón-Patiño, A. M. McKenna, C. Blanco-Tirado, et M. Y. Combariza, «Correlations between Molecular Composition and Adsorption, Aggregation, and Emulsifying Behaviors of PetroPhase 2017 Asphaltenes and Their Thin-Layer Chromatography Fractions », Energy \& Fuels, vol. 32, n 3, p. 2769-2780, march 2018, doi: 10.1021/acs.energyfuels.7b02859.

[19] W. Li, T. J. Morgan, A. A. Herod, et R. Kandiyoti, « Thin-layer chromatography of pitch and a petroleum vacuum residue », Journal of Chromatography A, vol. 1024, $\mathrm{n}^{\circ}$ 1-2, $\mathrm{p}$. 227-243, jan. 2004, doi: 10.1016/j.chroma.2003.10.020.

[20] M. L. Chacón-Patiño, S. M. Rowland, et R. P. Rodgers, «Advances in Asphaltene Petroleomics. Part 2: Selective Separation Method That Reveals Fractions Enriched in Island and Archipelago Structural Motifs by Mass Spectrometry », Energy \& Fuels, vol. 32, n ${ }^{\circ}$ 1, p. 314-328, jan. 2018, doi: 10.1021/acs.energyfuels.7b03281.

[21] M. L. Chacón-Patiño, S. M. Rowland, et R. P. Rodgers, "Advances in Asphaltene Petroleomics. Part 1: Asphaltenes Are Composed of Abundant Island and Archipelago Structural Motifs », Energy \& Fuels, vol. 31, no 12, p. 13509-13518, dec. 2017, doi: 10.1021/acs.energyfuels.7b02873.

[22] M. L. Chacón-Patiño, S. M. Rowland, et R. P. Rodgers, "The Compositional and Structural Continuum of Petroleum from Light Distillates to Asphaltenes: The Boduszynski Continuum Theory As Revealedby FT-ICR Mass Spectrometry », in ACS Symposium Series, vol. 1282, C. Ovalles et M. E. Moir, Éd. Washington, DC: American Chemical Society, 2018, p. 113-171.

[23] D. Günther, I. Horn, et B. Hattendorf, « Recent trends and developments in laser ablationICP-mass spectrometry », Fresenius' Journal of Analytical Chemistry, vol. 368, nº 1, p. 4-14, aug. 2000, doi: 10.1007/s002160000495.

[24] N. Vorapalawut et al., «Application of TLC and LA ICP SF MS for speciation of S, Ni and V in petroleum samples ", Talanta, vol. 97, p. 574-578, aug. 2012, doi: 10.1016/j.talanta.2012.04.040.

[25] J. Chirinos, D. Oropeza, J. González, M. Ranaudo, et R. E. Russo, « Determination of Vanadium/Nickel Proportionality in the Asphaltene Fraction of Crude Oil Using Thin-Layer Chromatography with Femtosecond Laser Ablation-Inductively Coupled Plasma-Mass Spectrometry », Energy \& Fuels, vol. 27, $\mathrm{n}^{\mathrm{0}}$ 5, p. 2431-2436, may 2013, doi: 10.1021/ef3020052.

[26] Y. Cho, M. Witt, J. M. Jin, Y. H. Kim, N.-S. Nho, et S. Kim, «Evaluation of Laser Desorption Ionization Coupled to Fourier Transform Ion Cyclotron Resonance Mass Spectrometry To Study Metalloporphyrin Complexes », Energy \& Fuels, vol. 28, no 11, p. 6699-6706, nov. 2014, doi: 10.1021/ef500997m. 
[27] J. S. Ramírez-Pradilla, C. Blanco-Tirado, et M. Y. Combariza, « Electron-Transfer Ionization of Nanoparticles, Polymers, Porphyrins, and Fullerenes Using Synthetically Tunable $\alpha$-Cyanophenylenevinylenes as UV MALDI-MS Matrices », ACS Applied Materials \& Interfaces, vol. 11, $\mathrm{n}^{\circ}$ 11, p. 10975-10987, march 2019, doi: 10.1021/acsami.8b22246.

[28] J. C. Putman et al., « Analysis of Petroleum Products by Gel Permeation Chromatography Coupled Online with Inductively Coupled Plasma Mass Spectrometry and Offline with Fourier Transform Ion Cyclotron Resonance Mass Spectrometry », Energy \& Fuels, nov. 2018, doi: 10.1021/acs.energyfuels.8b02788.

[29] D. Giraldo-Dávila, M. L. Chacón-Patiño, J. S. Ramirez-Pradilla, C. Blanco-Tirado, et M. Y. Combariza, « Selective ionization by electron-transfer MALDI-MS of vanadyl porphyrins from crude oils », Fuel, vol. 226, p. 103-111, aug. 2018, doi: 10.1016/j.fuel.2018.04.016.

[30] O. Lacroix-Andrivet, M. Hubert-Roux, A. L. Mendes Siqueira, Y. Bai, et C. Afonso, "Comparison of Silica and Cellulose Stationary Phases to Analyze Bitumen by HighPerformance Thin-Layer Chromatography Coupled to Laser Desorption Ionization Fourier Transform Ion Cyclotron Resonance Mass Spectrometry », Energy Fuels, p. acs.energyfuels.0c00709, july 2020, doi: 10.1021/acs.energyfuels.0c00709.

[31] S. Kim, R. W. Kramer, et P. G. Hatcher, « Graphical Method for Analysis of UltrahighResolution Broadband Mass Spectra of Natural Organic Matter, the Van Krevelen Diagram », Analytical Chemistry, vol. 75, ${ }^{\circ}$ 20, p. 5336-5344, oct. 2003, doi: 10.1021/ac034415p.

[32] R. Moulian et al., « Speciation of Metals in Asphaltenes by High-Performance Thin-Layer Chromatography and Laser Ablation Inductively Coupled Plasma-Mass Spectrometry ", Energy \& Fuels, vol. 33, n ${ }^{\circ}$ 7, p. 6060-6068, july 2019, doi: 10.1021/acs.energyfuels.9b00676.

[33] J. C. Putman et al., « Probing Aggregation Tendencies in Asphaltenes by Gel Permeation Chromatography. Part 1: Online Inductively Coupled Plasma Mass Spectrometry and Offline Fourier Transform Ion Cyclotron Resonance Mass Spectrometry », Energy \& Fuels, june2020, doi: 10.1021/acs.energyfuels.0c01522. 


\section{TABLES}

Table 1. LA-ICP MS Operating Parameters

\begin{tabular}{lr}
\hline \multicolumn{3}{c}{ Agilent 7700 series ICP MS } \\
\hline $\begin{array}{l}\text { Plasma Ar gas flow rate } \\
\left(\text { L.min }^{-1}\right)\end{array}$ & 15 \\
$\begin{array}{l}\text { Auxiliary Ar gas flow rate } \\
\left(\text { L.min }{ }^{-1}\right)\end{array}$ & 1 \\
Measured Isotope & ${ }^{13} \mathrm{C},{ }^{32} \mathrm{~S},{ }^{51} \mathrm{~V},{ }^{58} \mathrm{Ni}$, \\
Analysis time (s) & ${ }^{60} \mathrm{Ni}$ \\
\hline \multicolumn{1}{c}{ New Wave Research UP-213 LA } & 506 \\
\hline Wavelength $(\mathrm{nm})$ & 213 \\
Fluence $\left(\mathrm{J} . \mathrm{cm}^{-2}\right)$ & 0.85 \\
Spot size $(\mu \mathrm{m})$ & 200 \\
Scan speed $\left(\mu . \mathrm{ms}{ }^{-1}\right)$ & 100 \\
Carrier He gas flow rate \\
$\left(\right.$ L.min $\left.{ }^{-1}\right)$
\end{tabular}


Table 2. Results for UV analysis at $280 \mathrm{~nm}$ for all four samples with the average intensity for a total of 6 replicates and the RSD.

\begin{tabular}{cccccc}
\hline Area $280 ~ \mathbf{~ n m}$ & Area at noneluted point & $\begin{array}{c}\text { Area at eluted } \\
\text { point }\end{array}$ & $\begin{array}{c}\text { RSD at noneluted RSD at eluted } \\
\text { point (\%) }\end{array}$ & $\begin{array}{c}\text { point (\%) } \\
\text { point }\end{array}$ \\
\hline Whole PetroPhase 2017 & $19000 \quad(72 \%)$ & 8000 & $(28 \%)$ & 11.1 & 23.4 \\
Tol/THF/MeOH fraction & $15000(91.2 \%)$ & $1000 \quad(8.8 \%)$ & 7.4 & 16.9 \\
Hep/Tol fraction & $19000(76.9 \%)$ & $6000(23.1 \%)$ & 6.6 & 19.8 \\
Acetone fraction & $6000 \quad(47 \%)$ & $8000 \quad(53 \%)$ & 6.6 & 20.7 \\
\hline
\end{tabular}


Table 3. Results for LA-ICP-MS analysis at mass 51 for all four samples with the average intensity for a total of 6 replicates and the RSD

\begin{tabular}{|c|c|c|c|c|}
\hline Area $^{51} \mathrm{~V}$ & Area at noneluted point & $\begin{array}{c}\text { Area at eluted } \\
\text { point }\end{array}$ & $\begin{array}{c}\text { RSD at } \\
\text { noneluted point } \\
(\%)\end{array}$ & $\begin{array}{l}\text { RSD at eluted } \\
\text { point }(\%)\end{array}$ \\
\hline Whole Petrophase 2017 & $552000(78.9 \%)$ & $148000(21.1 \%)$ & 11.4 & 9.8 \\
\hline Tol/THF/MeOH fraction & $667000(100 \%)$ & $(0 \%)$ & 6.3 & 0.0 \\
\hline Hep/Tol fraction & $500000(95.8 \%)$ & $22000 \quad(4.2 \%)$ & 2.3 & 31.9 \\
\hline Acetone fraction & $0 \quad(0 \%)$ & $143000(100 \%)$ & 0.0 & 4.1 \\
\hline
\end{tabular}




\section{FIGURES}

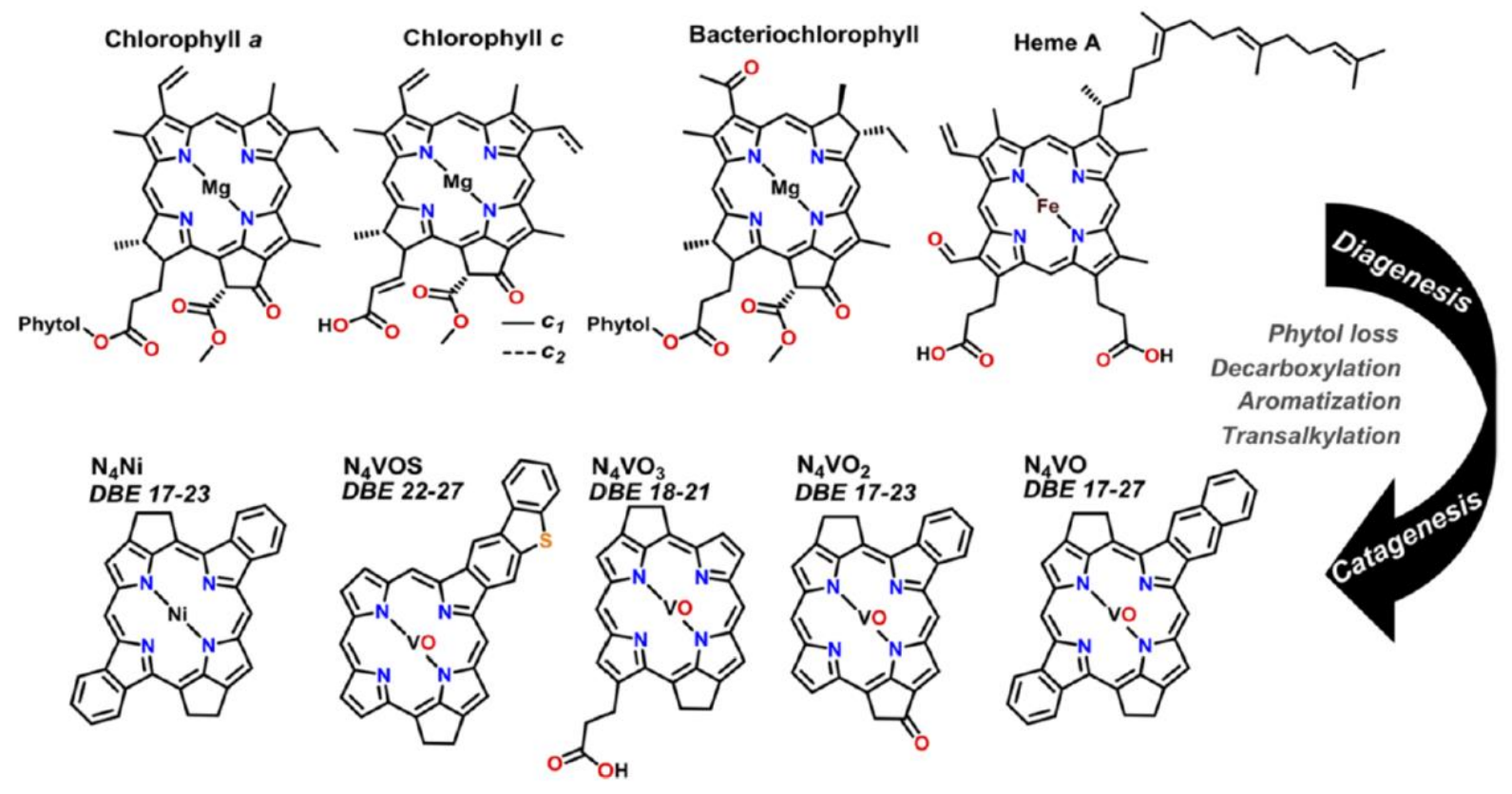

Figure 1. Scheme of geochemical transformation of chlorophylls [4]. 

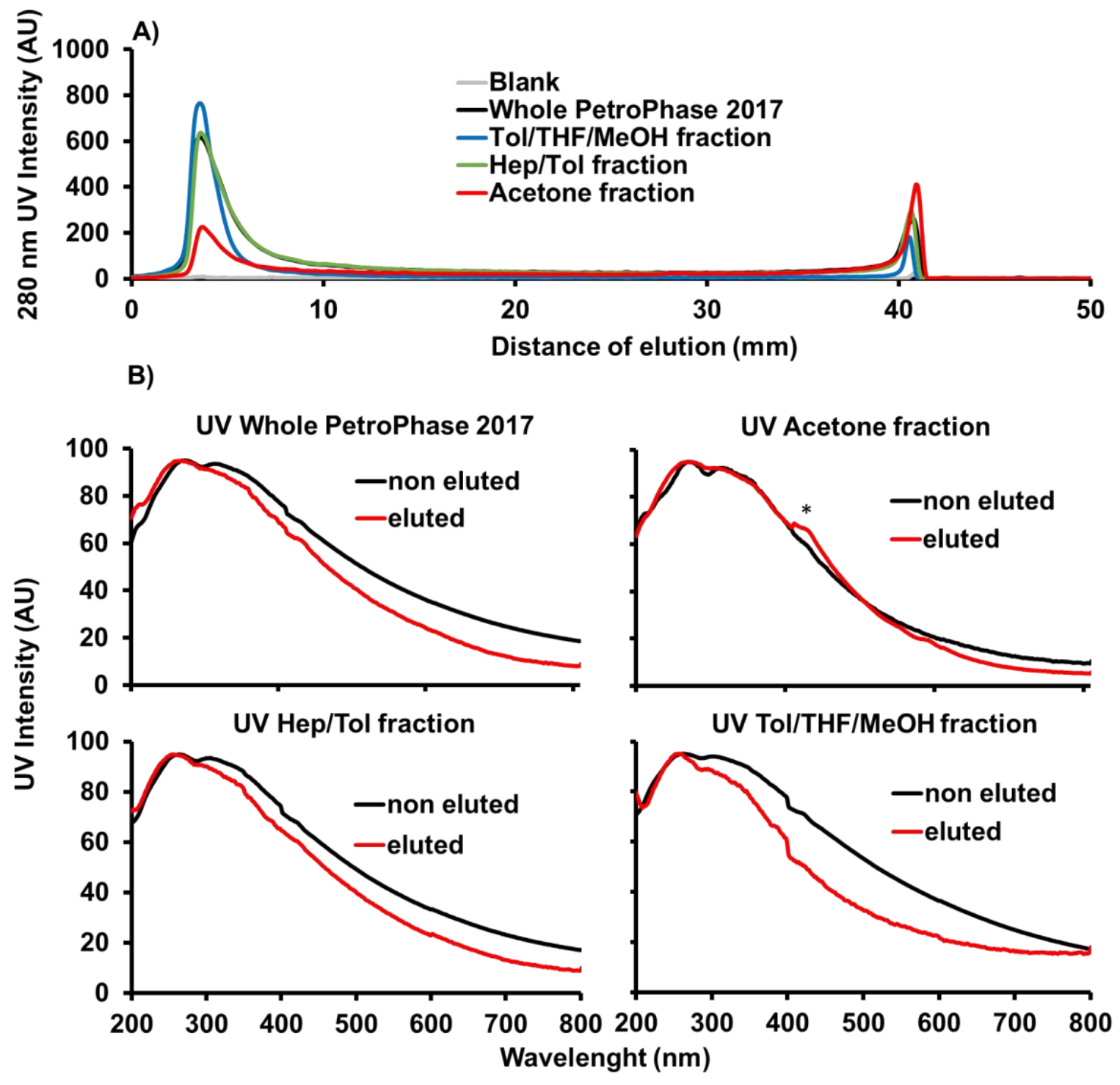

Figure 2. UV chromatograms at $280 \mathrm{~nm}$ (A) and UV spectra (D) and chromatograms (B) obtained by HPTLC-UV at $280 \mathrm{~nm}$ for all four samples and a blank. 

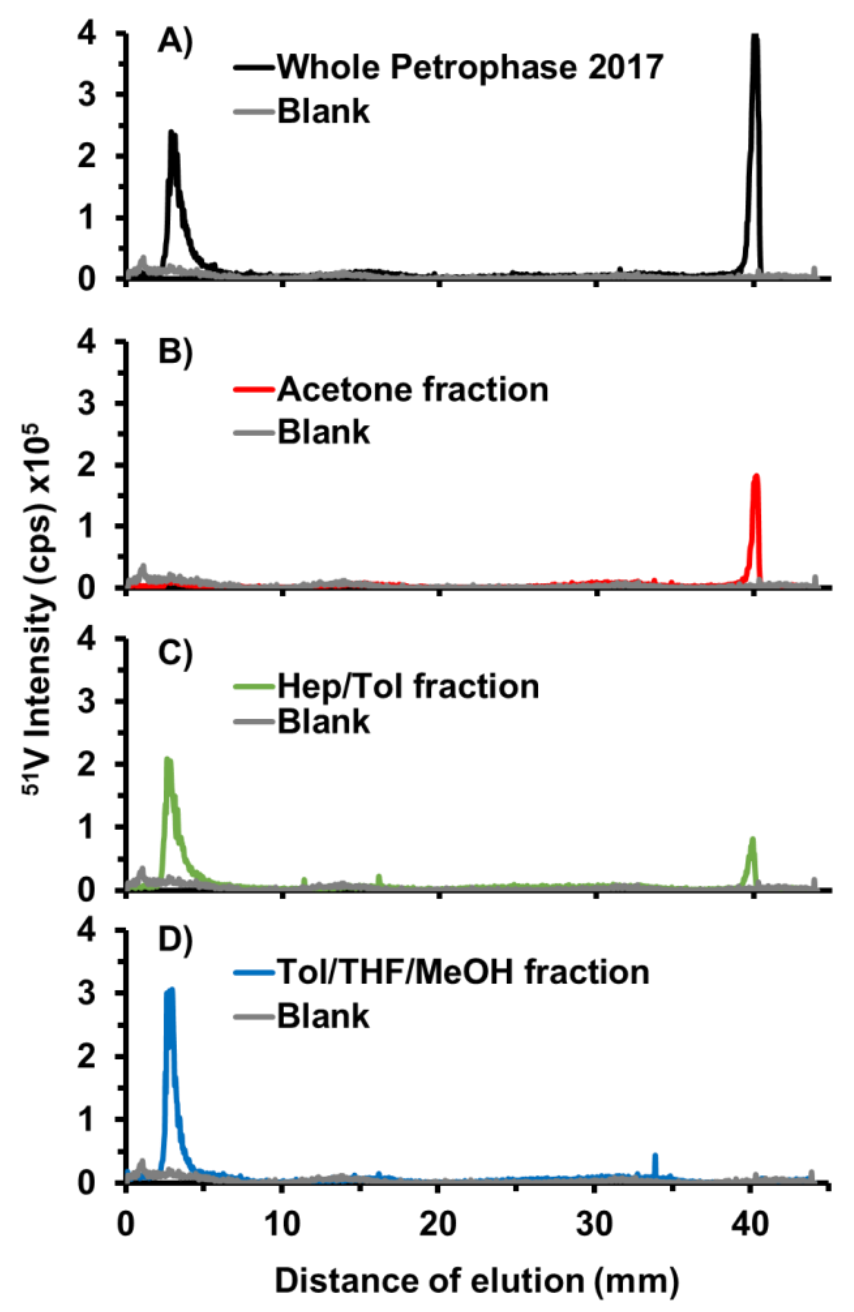

Figure 3. Chromatograms obtained by HPTLC-LA-ICP-MS analysis at mass 51 for all four samples and a blank. 


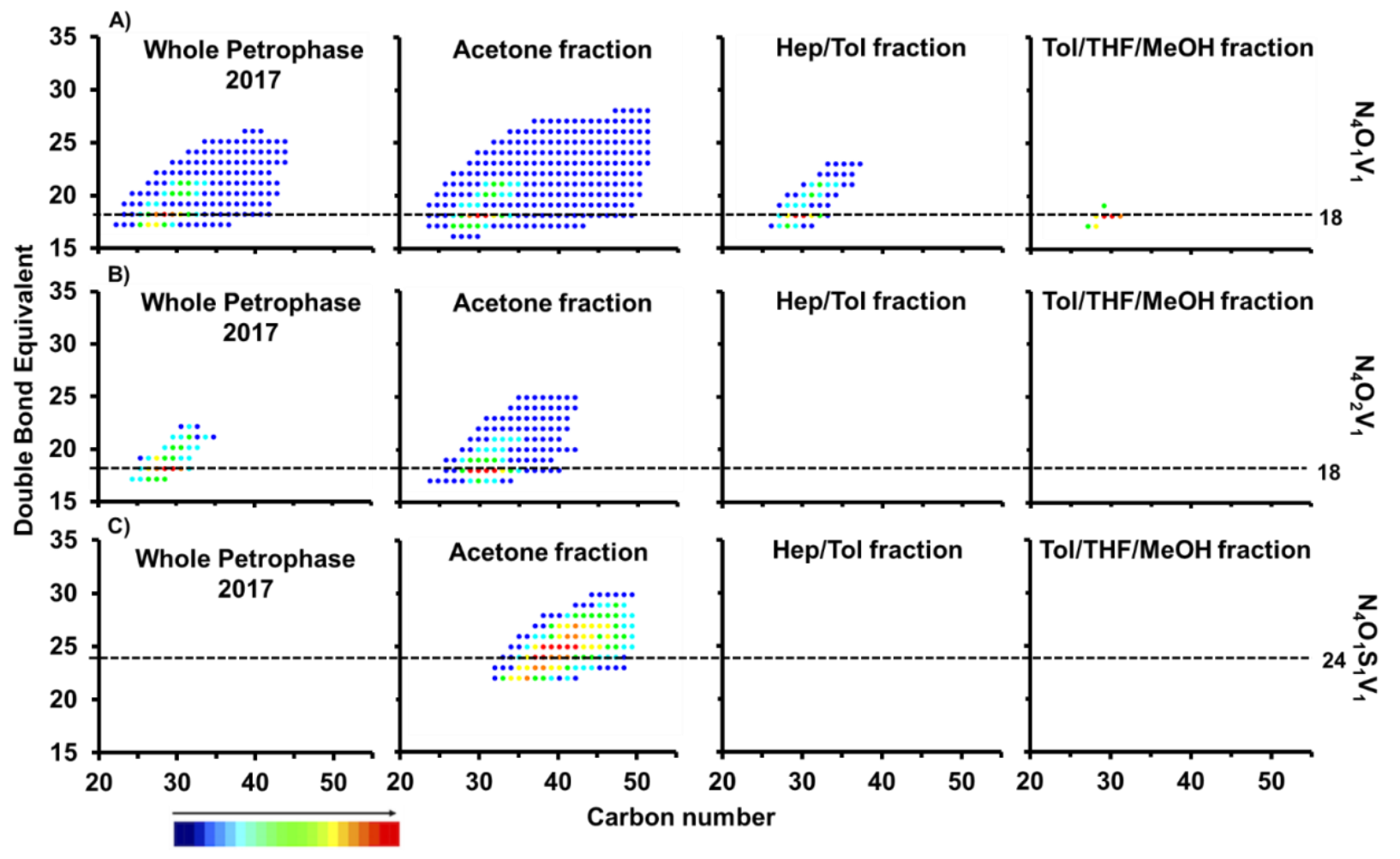

Figure 4. DBE/\# maps of $\mathrm{V}_{1} \mathrm{O}_{1} \mathrm{~N}_{4}(\mathrm{~A}), \mathrm{V}_{1} \mathrm{O}_{2} \mathrm{~N}_{4}(\mathrm{~B})$, and $\mathrm{V}_{1} \mathrm{O}_{1} \mathrm{~N}_{4} \mathrm{~S}_{1}(\mathrm{C})$ for all four samples by MALDI FT-ICR MS at the eluted point. 